\title{
S-wave Anisotropy Analysis by Seismic Interferometry Applied to Seismic Data Observed by DONET Observatories in the Nankai Trough
}

\author{
Toshinori KIMURA ${ }^{1,2}$, Hitoshi MIKADA ${ }^{2}$, Eiichiro ARAKI ${ }^{1}$ and Kazuya KITADA ${ }^{1}$ \\ ${ }^{1}$ Earthquake and Tsunami Research Project for Disaster Prevention, JAMSTEC. \\ ${ }^{2}$ Dept. of Civil and Earth Res. Eng., Kyoto University
}

\begin{abstract}
Seismic interferometry is an evolutionary new technique in seismic data processing field to obtain virtual shot records. We apply seismic interferometry to earthquake dataset acquired by DONET seafloor seismometers deployed in the Nankai Trough area. We use two horizontal components of seismometer to obtain virtual shot record. We expect that the two horizontal components are dominated by S-wave component. Therefore, the obtained virtual shot record should reflect the subseafloor S-wave velocity structure in the shallow part of the plate subduction zone. We then estimated direction of S-wave anisotropy from Alford rotation applied to obtained virtual shot records. Results show that the estimated directions of S-wave anisotropy are corresponding to the direction of principal share stress estimated from other methods, such as the borehole breakout analysis conducted in the IODP borehole sites, which are located near DONET observatories. Our results imply that seismic interferometry can be used as powerful tool to estimate $\mathrm{S}$-wave anisotropy to monitor stress accumulation process which is underway in the plate subduction seismogenic zone.
\end{abstract}

\section{INTRODUCTION}

The Nankai Trough, which is located beneath the Pacific Ocean off the southeast coast of Japan, is a plate boundary formed by the subducting Philippine Sea plate beneath the overhung Eurasian plate at the rate of $4.5 \mathrm{~cm} / \mathrm{yr}^{1}$. The subduction of the plate has caused repeating great earthquakes along subuduction mega-thrusts faults between the two plates. The Magnitude 9.0 Tohoku-oki earthquake $^{2,3)}$ that took place on March 11, 2011, is one of examples of interplate megathrust earthquakes, although the location is at the Japan Trench subduction zone. Megathrust earthquakes that took place almost every hundred of years at the Nankai Trough in the records of the past 1400 years are all known as tsunamogenic ones as well. Because of hazardous nature of interplate earthquakes, it is essential to understand the processes that govern the distribution, mechanics, and style of slip along subduction for earthquake and tsunami hazard assessment.

The huge height of the tsunami caused by the 2011 Tohoku-oki earthquakes brought new insight to the mechanism of tsunamogenic processes. After seismological analyses, it has become clear that the considerable contribution of shallow part of the megathrust fault augmented the height. This means that the stress drop in the shallow sediments is unexpectedly large ${ }^{2,4)}$ although we do not think such quantity of stress could be accumulated due to low material strength of the sediments. Therefore, it is necessary to investigate how the stress could be accumulated in the shallow sediments, what the role of interstitial fluid could be in the stress accumulation processes, etc. Material physical properties, including seismic velocities, densities, and porosities, of shallow sediments beneath the seafloor should also be estimated to understand the physical nature of stress accumulation.

In this study, as a first step to understand the physical nature as mentioned above, we aim to obtain the information of S-wave velocity and anisotropy beneath seafloor, which can be interpreted as a proxy of strain and stress field. For this purpose, we apply seismic interferometry to earthquake dataset acquired by horizontal components of the DONET (Dense Oceanfloor 
Network System for Earthquakes and Tsunamis) broadband seismometers which were deployed on seafloor in the Nankai Trough area by JAMSTEC. Seismic interferometry provides a virtual shot record after the cross-correlation of seismic records simultaneously acquired by the two seismometers 5),6). Because the horizontal components are dominated by $\mathrm{S}$-wave energy, we expected that obtained result would provide us the knowledge of S-wave velocity and anisotropy beneath seafloor as a proxy of strain and stress field, and fluid migration above the plate boundary. We finally applied the Alford rotation ${ }^{7}$ to the obtained virtual shot record to estimate anisotropy direction.

In this paper, we report the preliminary result of application of seismic interferometry to the earthquake dataset observed by seafloor observatory and Alford rotation to estimate

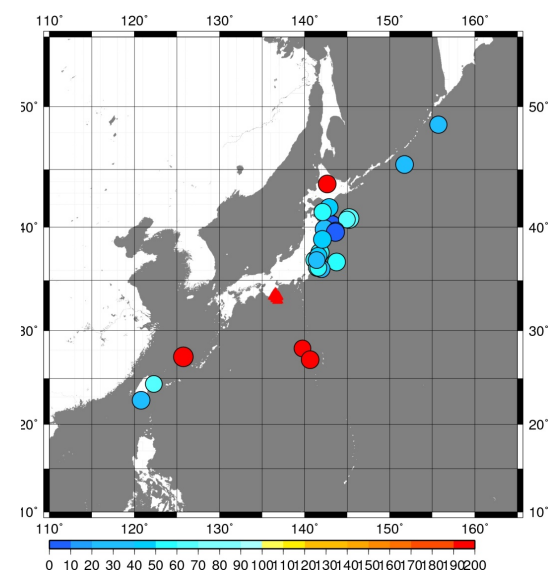

Figure 1 Map of earthquakes used for the seismic interferometry analysis. Circles show epicenters of earthquakes. Triangles show the locations of DONET observatories.

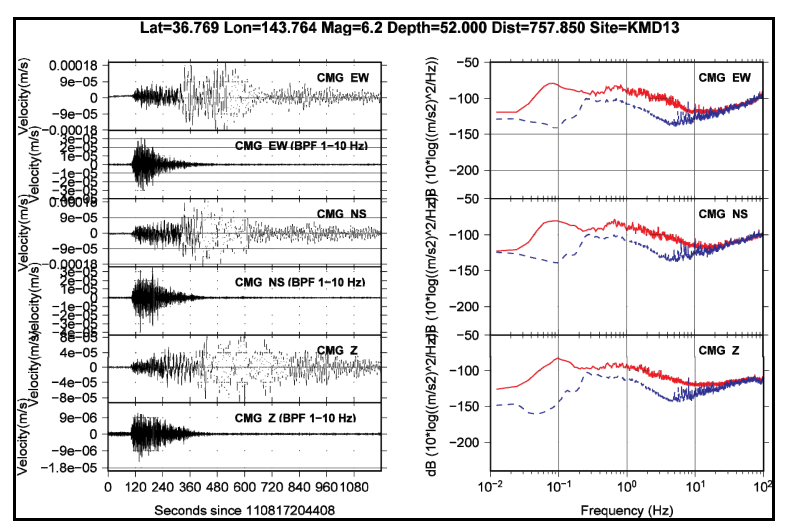

Figure 2 Example of obtained earthquakes. (Left) Timeseries of each component of raw and filtered data. (Right) PSD plot of obtained earthquake.

Dashed lines show background noise level. Solid lines show PSD of earthquake components quantitative anisotropy direction from obtained virtual shot records.

\section{DATA PROCESSING}

The procedures of the data processing are as follows: 1) Choose earthquake data. 2) Apply Bandpass filter to the earthquake data. 3) Calculate auto- and cross-correlation of two horizontal components. 4) Calculate average of each virtual shot record obtained from each earthquake. 4) Apply Alford rotation to the virtual shot records to obtain anisotropy direction beneath each DONET observatory. Data processing can be divided into three major steps: pre-processing, correlation and Alford rotation.

\section{(1)Pre-processings}

We have a lot of earthquakes everywhere in Japan. We use the earthquake catalog of the Japan Meteorological Agency (JMA) to choose earthquake dataset used for data processing. In this catalog, we found more than two hundred thousand earthquakes which occurred around Japan from August 2011 to July 2012. We finally chose twenty six earthquakes to be used as input data for the following processing. These earthquakes have more than $500 \mathrm{~km}$ epicentral distances from the DONET observatories with magnitude greater than 6.0. Fig. 1 shows a map of earthquakes used for the data processing. Figure 2 shows an example of chosen earthquake. Strong surface wave is visible in the timeseries. In this study, we use body wave component. Therefore, surface wave is eliminated by bandpass filter. We finally use $1-10 \mathrm{~Hz}$ bandpass filter.

\section{(2)Correlation}

After the above mentioned pre-processings were applied, we obtain zero offset 4-C virtual shot record after auto- and cross-correlation from horizontal components of each DONET seismometer. In the $\mathrm{x}-\mathrm{y}$ plane of the Cartesian coordinates, the 4-C virtual shot records can be written as follows

$$
\mathrm{V}=\left(\begin{array}{ll}
v_{11} & v_{12} \\
v_{21} & v_{22}
\end{array}\right)
$$

where $v_{i j}$ represents virtual shot records with $i$-direction source and $j$-direction receiver component. For example, $v_{12}$ represents the 


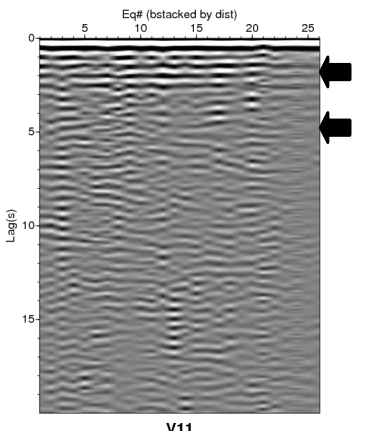

v11
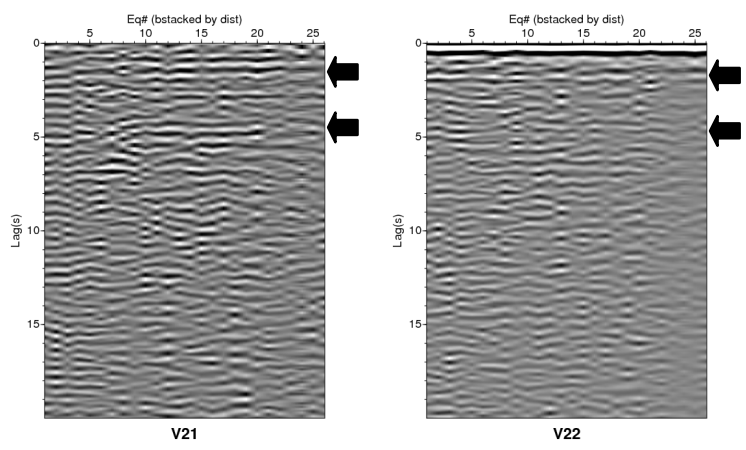

Figure 3 Obtained 4-C virtual shot records of DONET KMD13 observatory. Arrows indicate estimated reflections of each component. We found S-wave reflections around $2 \mathrm{~s}$ and $5 \mathrm{~s}$ which are visible in virtual shot records calculated from different earthquakes.

virtual shot record with $\mathrm{x}$-direction source and $y$-direction receiver obtained from cross-correlation between $\mathrm{x}$ - and $\mathrm{y}$-component of the seismometer. Fig.3 shows the obtained virtual shot record of DONET KMD13 observatory calculated from each earthquake data before calculating average. The horizontal axis in Fig.3 indicates earthquake number sorted by the distance between the epicenter and observatory. In this study, x-direction and $\mathrm{y}$-direction are E-W and N-S direction, respectively. In obtained virtual shot records, some reflections which have similar phases in different earthquakes are visible. However, the reflection phase in each component is not consistent with that of others. It might result from S-wave splitting affected by anisotropy. S-wave split into two orthogonal directions along anisotropy direction in propagating anisotropy media ${ }^{8)}$.

\section{(3)Alford rotation}

To estimate anisotropy information from the obtained 4-C virtual shot records, we applied Alford rotation to the 4-C virtual shot records. The Alford rotation is a widely used method to determine first and slow directions of S-wave anisotropy. The rotation can be performed as following equation.

$$
U=\left(\begin{array}{cc}
\left(\cos ^{2} \theta v_{11}+\sin ^{2} \theta v_{22}\right. & \left(\cos ^{2} \theta v_{12}-\sin ^{2} \theta v_{21}\right. \\
\left.+.5 \sin 2 \theta\left(v_{21}+v_{12}\right)\right) & \left.+.5 \sin 2 \theta\left(v_{22}-v_{11}\right)\right) \\
& \\
\left(\cos ^{2} \theta v_{21}-\sin ^{2} \theta v_{12}\right. & \left(\cos ^{2} \theta v_{22}+\sin ^{2} \theta v_{12}\right. \\
\left.+.5 \sin 2 \theta\left(v_{22}-v_{11}\right)\right) & \left.-.5 \sin 2 \theta\left(v_{21}-v_{12}\right)\right)
\end{array}\right)
$$

We can obtain counter clockwise rotated 4-C data from equation (2). If the rotated angle $\theta$ is agreed with the direction of the anisotropy, the off-diagonal element of matrix (2) can be minimized. In practical, we calculated power of off-diagonal elements of the matrix with the rotated angle changing and find the optimum value of the angle. Alford rotation is a useful tool to obtain anisotropy direction. However, this method is not used in case that the anisotropy is variant with depth. To solve this problem, we used the layer stripping method ${ }^{9)}$. This method is a modified method from standard Alford rotation to obtain anisotropy direction by calculating the rotated angle for each layer after removing anisotropy effect of above layers.

\section{RESULTS}

Fig. 4(a) shows the obtained 4-C virtual shot records of DONET KMD13 observatory after averaging results from all earthquakes. We applied the layer stripping method to the 4-C records with time window between 2 and 6 s. This time windows include S-wave reflections which may be reflections from bottom of shallow sediment, top of accretionary prism. The obtained angle from this time window, $\mathrm{N} 47^{\circ} \mathrm{W}$ is the anisotropy direction in the $1^{\text {st }}$ layer. Then 4-C data are rotated by the angle and remove effect of anisotropy of $1^{\text {st }}$ layer by removing $\mathrm{S}$-wave travel time difference between first and slow direction in the $1^{\text {st }}$ layer. We then calculated the $2^{\text {nd }}$ layer anisotropy with time windows between 6 and 12s. We obtained $1-2^{\circ}$ as rotated angle for minimizing off-diagonal elements. It implies that the anisotropy direction is invariant in deeper part beneath accretionary prism or obtained virtual shot records have not enough $\mathrm{S} / \mathrm{N}$ ration to resolve reflections from deeper boundary. Fig. 4(b) shows rotated 4-C virtual shot records. We finally obtained S-wave anisotropy directions at five DONET observatories as summarize in Table 1. We compare the obtained S-wave directions to principal share stress estimated from other method. Lin et al. (2010) ${ }^{10)}$ present principal horizontal stress directions obtained from borehole breakout analyses of IODP site. Tsuji et al. (2011) ${ }^{11)}$ also present principal horizontal stress directions estimated from S-wave anisotropy calculated from 
(a) Amplitude Amplitude Amplitude Amplitude

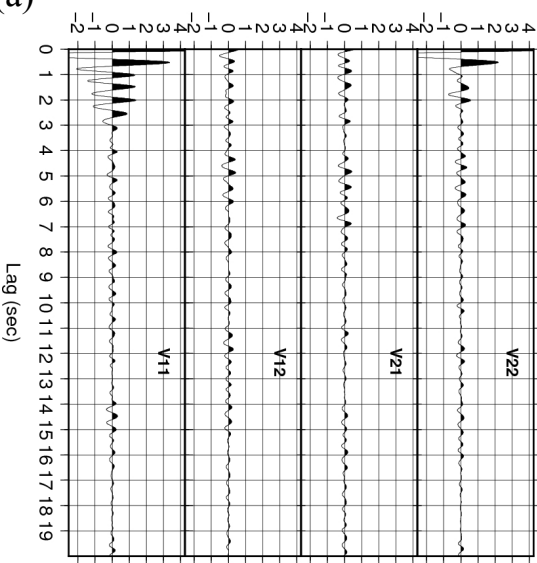

(b) Amplitude Amplitude Amplitude Amplitude

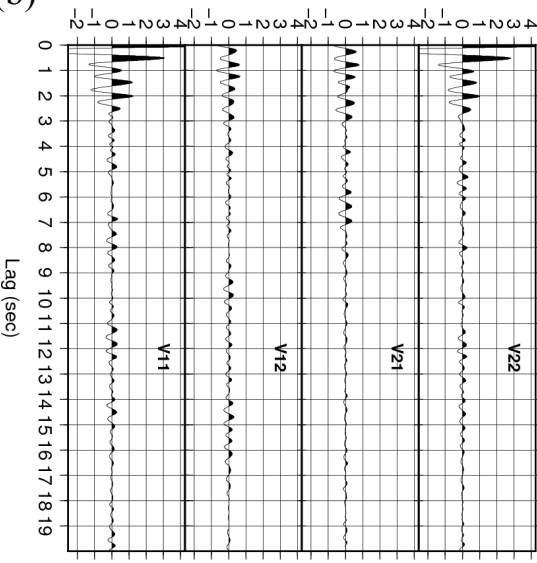

Figure 4 Stacked 4-C virtual shot records obtained from earthquake data acquired by DONET KMD13 observatory. (a) before Alford rotation (b) after Alford rotation.

active source P-S converted OBS records. Both results show same trends. The difference between the both results and our result are distributed within a range of $\pm 10^{\circ}$ compared to each closer site.

\section{CONCLUSIONS}

We obtained virtual shot records from earthquake data acquired by DONET seismometers. We

Table 1 Obtained S-wave anisotropy directions at five DONET observatories.

\begin{tabular}{|l|l|}
\hline Site & Direction \\
\hline KMC09 & $\mathrm{N} 41^{\circ} \mathrm{W}$ \\
\hline KMC12 & $\mathrm{N} 44^{\circ} \mathrm{W}$ \\
\hline KMD13 & $\mathrm{N} 47^{\circ} \mathrm{W}$ \\
\hline KMD16 & $\mathrm{N} 136^{\circ} \mathrm{W}$ \\
\hline KME17 & $\mathrm{N} 46^{\circ} \mathrm{W}$ \\
\hline
\end{tabular}

estimated S-wave anisotropy direction from the obtained virtual shot records by Alford rotation. Results show that the estimated directions of S-wave anisotropy are corresponding to the direction of principal share stress estimated from other methods. DONET is real time network, therefore, our results imply that seismic interferometry can be used as powerful tool to estimate $\mathrm{S}$-wave anisotropy to monitor stress accumulation process which is underway in the plate subduction seismogenic zone.

\section{REFERENCES}

1) Seno, T., Stein, S., and Gripp, A. E., 1993, A model for the motion of the Philippine Sea plate consistent with NUVEL-1 and geological data, J. Geophys. Res., 89, 17941-17948.

2) Hirose, F., Miyaoka, K., Hayashimoto, N., Yamazaki, T., and Nakamura, M., 2011, Outline of the 2011 off the Pacific coast of Tohoku earthquake (Mw 9.0): Seismicity: foreshocks, mainshock, aftershocks, and induced activity, Earth Planets Space, 63, 513-518.

3) Fujii, Y., Satake, K., Sakai, S., Shinohara, M., and Kanazawa T., 2011, Tsunami source of the 2011 off the Pacific coast of Tohoku, Japan earthquake, Earth Planets Space, 63, 815-820.

4) Matsubara, M., and Obara, K., 2011, The 2011 Off the Pacific Coast of Tohoku earthquake related to a strong velocity gradient with the Pacific plate, Earth Planets and Space, 63, 663-667.

5) Schuster, G. T., Yu, J., Sheng, J., and Rickett, J., 2004, Interferometric/daylight seismic imaging, Geophys. J. Int., 157, 838-852.

6) Wapenaar, K. and Fokkema, J., 2006, Green's function representations for seismic interferometry, Geophysics, 71, SI33-SI46.

7) Alford, R. M., 1986, Shear data in the presence of azimuthal anisotropy: Dilley, Texas, 56th Internat..Mtg., Soc. Expl. Geophys., Expanded Abstracts, 86, Session: s9.6

8) Crampin, S., 1981, A review of wave motion in anisotropic and cracked elastic-media, Wave Motion, 3, 343-391.

9) Thomsen, L., Tsvankin, I., and Mueller, M.C., 1999, Coarse-layer stripping of vertically variable azimuthal anisotropy from shear-wave data, Geophysics, 64, 1126-1138.

10) Lin, W., Doan, M. L., Moore, J. C. et al., 2010, Present-day principal horizontal stress orientations in the Kumano forearc basin of the southwest Japan subduction zone determined from IODP NanTroSEIZE drilling Site C0009: Geophys. Res. Let., 37, no. 13, L13303.

11) Tsuji, T., Dvorkin, J., Mavko, G., Nakata, N., Matsuoka, T., Nakanishi, A., Kodaira, S., and Nishizawa, O., 2011, Vp/Vs ratio and shear-wave splitting in the Nankai Trough seismogenic zone: Insights into effective stress, pore pressure and sediment consolidation, Geophysics, 76, No.3, WA71-WA82. 